\title{
Withdraw Sedation Gently or Face Withdrawal Syndrome!
}

\author{
Banani Poddar \\ Keywords: Analgesia, Sedation, Withdrawal syndrome. \\ Indian Journal of Critical Care Medicine (2020): 10.5005/jp-journals-10071-23466
}

Critically ill children and neonates were often cared for without sedation and analgesia until the early 1990s. ${ }^{1}$ Studies done at this time demonstrated that postoperative and ICU sedation and analgesia were important not only for humane care but also to decrease morbidity and even mortality. From these studies emerged the awareness that sedation and analgesia are important while caring for sick neonates and children. ${ }^{2}$

Today, sedation and analgesia are among the most important supportive therapies given to critically ill children, especially those on mechanical ventilation. However, like all other therapies, these therapies are not without ill effects. Children are unique as far as adverse effects of sedation-analgesia are concerned as they often encounter tolerance and withdrawal syndrome. ${ }^{3,4}$

Withdrawal was first described in the adult literature (opioid addiction related) and among neonates (when they were born to opioid-addicted mothers), but the recognition that this syndrome could be seen in pediatric patients was in the 1990s. ${ }^{5}$ Arnold et al. have given the first description of this entity in neonates and noted that the same could occur in infants too. Tobias et al. reported a protocol to prevent and treat opioid withdrawal. ${ }^{6,7}$

latrogenic withdrawal syndrome (IWS) is a clinical syndrome that manifests after stopping a sedative-opioid drug after prolonged exposure. ${ }^{5,8}$ The manifestations include autonomic dysfunction, gastrointestinal disturbances, and neurologic and motor abnormalities. ${ }^{4}$ Studies assessing the risk factors for the syndrome have found younger age (especially those under six months of age), those with preexisting cognitive impairment, higher severity of illness, and higher nursing workload to be important risk factors. Lack of a sedative weaning protocol has also been considered as one of the risk factors.

In this issue of the journal, Tiacharoen et al. report the withdrawal syndrome in children assigned to a sedation weaning protocol and compared this to usual care in a pilot randomized controlled study in critically ill children. ${ }^{9}$ Most of the intensivists do wean sedation and analgesia, but there is no fixed protocol for the same. The sedation weaning protocol used in this study is fairly well worked out and is derived from previous studies and includes inputs from clinical pharmacists. The authors have shown that it is feasible to implement such a sedation weaning protocol and the strength of the study lies in this protocol. Further validation of this protocol would require larger numbers to be studied and use by other units.

Unfortunately, the study has several limitations. While the authors did calculate a required sample size, they excluded many patients for rather flimsy reasons and the ultimate number studied is very small, and hence, no definitive results have been shown. The number of exclusions for probable drug interactions with methadone $(n=36)$ and exclusion of five patients for suspected allergies to sedative medications are definitely too large a number,
Department of Critical Care Medicine, Sanjay Gandhi Postgraduate Institute of Medical Sciences, Lucknow, Uttar Pradesh, India

Corresponding Author: Banani Poddar, Department of Critical Care Medicine, Sanjay Gandhi Postgraduate Institute of Medical Sciences, Lucknow, Uttar Pradesh, India, Phone: +91 522 2494549, e-mail: bananip@sgpgi.ac.in

How to cite this article: Poddar B. Withdraw Sedation Gently or Face Withdrawal Syndrome! Indian J Crit Care Med 2020;24(6):381-382.

Source of support: Nil

Conflict of interest: None

especially since the sample size determined was 46 (23 in each group) and the final number studied was only 30 (19 and 11 in intervention and control groups, respectively).

The tools used for assessment of sedation (State Behavioral Scale) and IWS (Withdrawal Assessment Tool 1 or WAT 1) were appropriate, though it is not clear whether the nurses assessing the WAT 1 scores were blinded to the sedation weaning group. latrogenic withdrawal syndrome was seen in $83 \%$ of the patients and was no different between the intervention and control groups. The prevalence of IWS in this study is quite high, even if we consider that the median duration of sedation infusion was 10 days. Most of the studies would suggest IWS prevalence rates of $35-57 \%$ after five or more days of the infusion of benzodiazepine and/or opioids. ${ }^{10,11}$ It is not clear from the study whether the sedation was interrupted every morning to titrate the further need, as has been recommended. ${ }^{12}$ Moreover, randomization started after a particular dose of fentanyl and midazolam infusions was reached; it is not clear how the sedation was weaned until this level. Also, the patients were classified into high risk and low risk for IWS, but numbers are so small that this did not influence the prevalence of IWS.

In spite of these limitations, the authors have demonstrated small benefits in terms of reduction in the number of days that the children demonstrated withdrawal symptoms ("withdrawal days"), rescue medications given for withdrawal symptoms, and the length of pediatric intensive care unit (PICU) stay. However, it should be noted that the control group had a higher PRISM III score which could have influenced the longer duration of the PICU stay. The duration of mechanical ventilation and sedation infusions also seem longer than necessary for the given severity of illness.

The PICU is often manned by trainees at different levels of experience and some of them may be unfamiliar with weaning of sedation/analgesia. In such circumstances, the weaning protocol is a welcome addition and may streamline this otherwise difficult process.

(0) The Author(s). 2020 Open Access This article is distributed under the terms of the Creative Commons Attribution 4.0 International License (https://creativecommons. org/licenses/by-nc/4.0/), which permits unrestricted use, distribution, and non-commercial reproduction in any medium, provided you give appropriate credit to the original author(s) and the source, provide a link to the Creative Commons license, and indicate if changes were made. The Creative Commons Public Domain Dedication waiver (http://creativecommons.org/publicdomain/zero/1.0/) applies to the data made available in this article, unless otherwise stated. 


\section{References}

1. Rogers MC. Do the right thing - pain relief in infants and children. $N$ Engl J Med 1992;326(1):55-56. DOI: 10.1056/NEJM199201023260109.

2. Anand KSJ, Hickey PR. Halothane-morphine compared with high dose sufentanil for anesthesia and postoperative analgesia in neonatal cardiac surgery. N Engl J Med 1992;326(1):1-9. DOI: 10.1056/ NEJM199201023260101.

3. Fernández-Carrión F, Gaboli M, González-Celador R, Gómez de Quero-Masía P, Fernández-de Miguel S, Murga-Herrera V, et al. Withdrawal syndrome in the pediatric intensive care unit. Incidence and risk factors. Med Intensiva 2013;37(2):67-74. DOI: 10.1016/j. medin.2012.02.009.

4. Best KM, Wypij D, Asaro LA, Curley MAQ. Patient, process and system predictors of iatrogenic withdrawal syndrome in children. Crit Care Med 2017;45(1):e7-e15. DOI: 10.1097/CCM.0000000000001953.

5. Tobias JD. Tolerance, withdrawal, and physical dependency after long-term sedation and analgesia of children in the pediatric intensive care unit. Crit Care Med 2000;28(6):2122-2132. DOI: 10.1097/00003246-200006000-00079.

6. Arnold JH, Truog RD, Orav EJ, Scavone JM, Hershenson MB. Tolerance and dependence in neonates sedated with fentanyl during extracorporeal membrane oxygenation. Anesthesiology 1990;73(6):1136-1140. DOI: 10.1097/00000542-199012000-00011.
7. Arnold J, Truog R, Scavone J, FENTON T. Changes in the pharmacodynamic response to fentanyl in neonates during continuous infusion. J Pediatr 1991;119(4):639-643. DOI: 10.1016/ s0022-3476(05)82419-9.

8. Harris J, Ramelet A-S, van Dijk M, Pokorna P, Wielenga J, Tume L. Clinical recommendations for pain, sedation, withdrawal and delirium assessment in critically ill infants and children: an ESPNIC position statement for healthcare professionals. Intensive Care Med 2016;42(6):972-986. DOI: 10.1007/s00134-016-4344-1.

9. Tiacharoen D, Lertbunrian R, Veawpanich J, Suppalarkbunlue $N$, Anantasit N. Protocolized sedative weaning vs usual care in pediatric critically ill patients: a pilot randomized controlled trial. Indian J Crit Care Med 2020;24(6):451-458.

10. Fonsmark L, Rasmussen YH, Carl P. Occurrence of withdrawal in critically ill sedated children. Crit Care Med 1999;27(1):196-199. DOI: 10.1097/00003246-199901000-00052.

11. Katz R, Kelly HW, Hsi A. Prospective study on the occurrence of withdrawal in critically ill children who receive fentanyl by continuous infusion. Crit Care Med 1994;22(5):763-767. DOI: 10.1097/00003246199405000-00009.

12. Curley MA, Wypij D, Watson RS, Grant MJ, Asaro LA, Cheifetz IM, et al. Protocolised sedation versus usual care in pediatric patients mechanically ventilated for acute respiratory failure: a randomised clinical trial. JAMA 2015;313(4):379-389. DOI: 10.1001/jama.2014.18399. 